\title{
Da produção ao consumo: diversidade cultural nos usos coletivos de tecnologia entre grupos populares
}

\section{From production to consumption: cultural diversity in the collective uses of technology among low income groups}

Carla Barros $^{1}$

\begin{abstract}
Resumo A proposta do artigo é discutir usos de tecnologia entre grupos populares, nos quais a dimensão coletiva aparece como um aspecto central das dinâmicas culturais. Para tanto, são apresentados resultados de uma pesquisa etnográfica em andamento na cidade do Rio de Janeiro, cujo material é colocado em perspectiva com estudos realizados na África do Sul. O debate focaliza a descontinuidade entre as dimensões da produção e do consumo, não em termos da recepção de conteúdos, mas sim das próprias experiências de uso. As vivências em torno de televisão e celulares sugerem a relativização do modo de consumo individual em prol de uma investigação acerca de apropriações coletivas em contextos diversos aos dos países desenvolvidos, onde tais bens de consumo - assim como parte dominante das teorias acadêmicas - são produzidos.

Palavras-chave: Televisão; Celular; Usos coletivos; Grupos populares
\end{abstract}

\begin{abstract}
This article aims to discuss certain uses of technology among low income groups in Brazil and South Africa, in which the collective dimension stands as a central aspect of the observed cultural dynamics. With this intention, results about an ongoing ethnographic study were analyzed making a counterpoint between consumption practices in Brazil and in South Africa. These practices related to television and mobile phones suggest the need to relativize the pattern
\end{abstract}

\footnotetext{
${ }^{1}$ Universidade Federal Fluminense - UFF, Niterói, RJ, Brasil.

E-mail: barros.carla@uol.com.br
} 
130 DA PRODUÇÃO AO CONSUMO

of consumption for an individual consumer in order to better understand collective uses of these technologies in countries with great cultural diversity comparing those with developed countries, where such consumer goods, as well as a major part of academic theories, are produced.

Keywords: Television; Mobile phones; Collective uses; Low income groups 


\section{Introdução}

O presente artigo tem como objetivo discutir determinadas práticas de consumo de tecnologias comunicacionais junto a grupos populares nos quais os usos coletivos surgem como um aspecto central das dinâmicas culturais em questão. Para tanto, resultados de uma etnografia em andamento desenvolvida na cidade do Rio de Janeiro serão analisados e posteriormente colocados em perspectiva com estudos realizados na África do Sul. A procura por uma dimensão comparativa entre o contexto brasileiro e o sul-africano surge, em primeiro lugar, como uma tentativa de pensar a descontinuidade entre produção e consumo fora da experiência cultural dos países economicamente mais desenvolvidos. Além disso, como se sabe, tal descontinuidade tem uma longa tradição no que tange aos estudos de recepção, sejam eles de matriz britânica ou latino-americana. Em paralelo a tais estudos, um outro tipo de investigação pode ser conduzida, voltada agora para o entendimento de diferentes vivências com as próprias tecnologias que também enfatizem os modos pelos quais sujeitos particulares criam significados nas suas interações com os bens comunicacionais. É nesta última perspectiva, ainda pouco explorada, que o presente artigo pretende se deter.

Como já enfatizaram alguns estudiosos (ROCHA, 1985; MILLER, 1987; SAHLINS, 1979, entre outros), a produção “se completa" no consumo, já que é nesta última dimensão que os objetos produzidos em série ganham singularidade devido às apropriações de sujeitos inseridos em determinada cultura. Logo, os modos pelos quais os bens foram planejados na esfera da produção podem ser bastante alterados em seus usos cotidianos, através das mais diversas práticas de consumo.

O ponto de interesse do artigo está em investigar certos usos de tecnologia junto a grupos populares no Brasil - acrescentando comentários de estudos realizados na África do Sul -, procurando analisar como os sujeitos lidam, em seu dia a dia, com bens de consumo criados a partir de modelos predominantes nos contextos europeu e norte-americano. O esforço maior da análise se concentra em pesquisas realizadas acerca do hábito de assistir TV em celular e da prática de games em lan houses 
populares. O contraponto a ser feito com a África do Sul serve como indicação da importância de estudos comparativos que contemplem a diversidade cultural de países do Atlântico Sul em relação aos economicamente mais desenvolvidos.

No campo dos estudos de televisão, especificamente, Silveira (2004) já havia ressaltado que tanto os estudos etnográficos sobre consumo dos meios na tradição britânica dos Estudos Culturais quanto os produzidos no contexto latino-americano dos estudos de recepção identificam quase sempre o espaço doméstico e o grupo familiar como "unidades estruturais básicas da situacionalidade estandardizada da audiência televisiva" (SILVEIRA, 2004, p. 65). São estudos que tentam compreender os ritmos das dinâmicas domésticas nas suas vivências relacionadas aos programas televisivos, como na etnografia exemplar de Silverstone (1996), na qual, além de uma análise do núcleo familiar, é feita uma descrição dos móveis e demais objetos da casa, com o intuito de compor um cenário onde as experiências com o meio televisivo se sucedem.

Silveira chama atenção, portanto, para o fato de que os estudos etnográficos sobre a recepção televisiva nas vertentes britânica e latino-americana enfatizam primordialmente a "domesticidade" da audiência. Nessa perspectiva, argumenta, a interpretação dos conteúdos midiáticos dependeria de um mergulho profundo no cotidiano dos sujeitos pesquisados - ou seja, a compreensão dos sentidos surgidos na esfera da audiência deveria ser buscada a partir de um olhar minucioso sobre o lar, a moradia e a família, que, em conjunto, formam a vivência cotidiana. A partir daí, o autor questiona a existência de "um modo natural e universal" de ver televisão associado à domesticidade e ao grupo familiar, procurando apontar para seu caráter histórico e socialmente construído.

Assim, os estudos privilegiavam a televisão em seu lócus doméstico, dando pouca importância a, ou mesmo ignorando, outros espaços e contextos fora da casa onde o meio estivesse presente. Por que a tendência nos estudos de pensar a TV atrelada a ambientes domésticos? Estaria aí presente um certo "eurocentrismo" devido à influência da experiência familiar da maior parte dos estudiosos do tema com o contexto televisivo 
da casa? Para fugir dessa perspectiva, a "naturalização" da TV no ambiente doméstico começa a ser relativizada com o desenvolvimento de estudos empíricos que apresentam outras vivências midiáticas constituídas em cenários públicos e urbanos.

Embora relativamente pouco estudada, a audiência sempre esteve em outros espaços fora da casa, o que se intensificou com a chegada de novas tecnologias - em especial, a convergência tecnológica - e o avanço da mobilidade, que levaram a televisão e seu apelo audiovisual para fora dos limites da casa.

Vale registrar, por ora, alguns casos brasileiros anteriores ao advento das novas mídias e cujas dinâmicas permanecem nas vivências cotidianas. Em várias cidades brasileiras do interior, é possível observar cenas em que a TV é levada para as calçadas das ruas, mobilizando, em torno de si, a vizinhança ou mesmo quem estiver passando para acompanhar em conjunto a programação veiculada. Tufte (1997) realizou um estudo de recepção no interior do Rio Grande do Sul, relativo à novela Rainha da Sucata, no qual mostra que as fronteiras do público e do privado se dissolvem quando "as janelas e portas se abrem", permitindo que se veja a TV da rua - aqui, o pressuposto da domesticidade televisiva é desmontado pela observação de outras práticas sociais formadas por "situacionalidades híbridas".

Gastaldo (2005), em um estudo, explora a ideia de audiência coletiva em espaços urbanos, apoiando-se em uma etnografia realizada em bares na cidade de Porto Alegre onde são exibidas partidas de futebol. O autor analisa vários aspectos dessa audiência, detendo-se, especialmente, nas performances de masculinidade e na recepção coletiva do jogo. Quanto ao primeiro aspecto, faz uso da ideia de "relações jocosas" de Radcliffe Brown para entender o tipo de provocação que ocorre entre torcedores de times diferentes; por meio de brincadeiras e desafios verbais durante o jogo, as pessoas exercem um tipo de sociabilidade em que a brincadeira se sobrepõe ao conflito aberto. O que poderia acabar em briga se ocorresse em outros contextos, termina em um clima de apaziguamento das diferenças em favor da vivência de sociabilidade. Utilizando ainda 
o conceito de "interação focada”, de Goffman (1963), observa como os torcedores se voltam para o aparelho de TV e fazem comentários sobre o jogo para toda a plateia, sem ter que se fixar em uma determinada pessoa - é o que o autor chama de "falar para todos", uma modalidade de reação ao discurso midiático perante a plateia de torcedores presentes. A exibição do jogo pela TV vai suscitando uma série de reações do público que, em geral, faz comentários críticos e sarcásticos em relação às falas do locutor da partida, dos comentaristas e dos repórteres em campo, bem como às imagens exibidas.

Procurando investigar contextos de audiência existentes em ambientes urbanos, a reflexão presente neste artigo se detém em um tipo de situação diverso do comentado anteriormente. Trata-se, especificamente, da adoção de telefones celulares como plataformas de recepção televisiva, o que provoca uma reflexão sobre a tradicional divisão público/privado. O interesse aqui é o de pensar em aparelhos criados para consumo individual, como é o caso dos celulares, que, por conta de determinadas situações existentes em espaços públicos, acabam sendo apropriados em termos de usos coletivos, como será visto adiante.

Além dos usos relacionados a modos de assistir TV no celular, pretende-se estender a discussão para outras situações em que possa haver um distanciamento do modo individualizante de lidar com tecnologias da informação, predominante nos contextos europeu e norte-americano. Para iniciar a análise do caso brasileiro, segue uma breve apresentação do aparelho mais comumente encontrado no estudo em curso, os chamados celulares MPX ou "xing-lings".

\section{A emergência dos “xing-lings”}

A situação escolhida para observação no estudo é a que envolve os chamados celulares MPX ou "xing-lings". O nome "MPX" diz respeito aos aparelhos celulares amplamente consumidos no âmbito dos mercados populares nos grandes centros urbanos do país. Vale lembrar que os consumidores presentes nesses locais são pertencentes não apenas às camadas populares, mas também às camadas médias urbanas, embora os 
primeiros dominem o ambiente. Os referidos aparelhos são, em geral, contrabandeados e falsificados com referência a marcas famosas - como Sony, Nokia, Motorola e Apple -, sendo, em grande parte, de origem chinesa, daí o nome "xing-ling”. Os preços variam entre R \$ 150,00 e $\mathrm{R}$ \$ 350,00 e seus grandes atrativos são a captação da TV aberta no sinal analógico e a oferta de mais de um chip, o que permite enfrentar os altos custos da telefonia no Brasil com a adesão aos programas promocionais das empresas.

Os aparelhos do tipo MPX são vendidos no Rio de Janeiro e em outros centros urbanos em camelódromos e shoppings populares de informática, tendo preços atraentes graças a sua entrada no país sem o pagamento de impostos. Em geral, os MPX têm tela sensível ao toque, câmera na frente e atrás, internet wireless, espaço para dois ou mais chips e captação de TV aberta. No mercado formal, são aceitas apenas as denominações mp3 e mp4, que correspondem, respectivamente, a formatos de compressão de arquivos de áudio e de vídeo. No trabalho de campo realizado nos mercados populares, foi possível perceber a extensão dessa classificação até o aparelho "MPX 20" - nem sempre os vendedores têm o mesmo entendimento acerca da razão da especificação técnica de cada aparelho, mas as diferenças dizem respeito à presença de atributos como GPS, número de chips (dois, três ou quatro chips no mesmo aparelho), wi-fi, TV aberta e TV digital, entre outros.

Apesar da questão da pirataria, ocorreu um curioso fenômeno no contexto dos mercados populares - a ampla difusão de gadgets do tipo MPX ajudou a criar mais rapidamente no país o hábito de se ver TV no celular. Verificou-se, assim, uma outra dinâmica, não tão habitual, uma "novidade" promovida pela tecnologia - no caso, a possibilidade de assistir TV no celular ter se difundido pioneira e amplamente entre um público de baixa renda. A aceitação dos produtos com TV analógica no mercado informal, especialmente nas camadas populares, despertou o interesse de empresas em comercializar esse tipo de celular no Brasil, agora legalmente. A primeira a se aventurar foi a EUTV, que, em 2009, obteve a homologação da agência reguladora no Brasil para 
comercializar um modelo produzido pela chinesa E-Techco. O executivo principal da EUTV na época do lançamento do aparelho deixou claro que sua estratégia comercial era fazer frente ao "mercado cinza" de celulares contrabandeados, oferecendo um modelo com dois SIM cards e acesso à TV aberta, dois dos mais fortes atrativos dos MPX.

Assim, a prática de assistir TV em celulares, além de se difundir pioneiramente em grupos populares, passou a inspirar empresas estabelecidas legalmente, como Samsung e Motorola, a abrir espaços para a venda de aparelhos nos moldes dos MPX amplamente consumidos no mercado informal. O importante a destacar é que a ampla difusão de celulares do tipo MPX ajudou a criar mais rapidamente no país o hábito de ver TV no celular no contexto das classes populares - e não no das classes médias e altas, como seria de se esperar. A "novidade" da TV no celular, assim, não se difundiu a partir de um efeito trickle-down (SIMMEL, 1957) - quando as classes subordinadas imitam os modismos que surgem nas classes mais altas -, mas a partir de um maior consumo encontrado nos grupos de baixa renda. Conforme Miller e Horst (2006) já haviam chamado atenção em sua etnografia sobre o uso de celulares nas camadas populares da Jamaica, muitas vezes as práticas de consumo seguem caminhos bem diversos dos projetados pelos criadores de tecnologia.

\section{Assistindo TV no celular: conversas em movimento}

Diferente dos casos em que a TV já se encontra inserida em um contexto de recepção pública e coletiva - como no exemplo de um aparelho ligado em um bar servindo à fruição do grupo de pessoas presentes -, aqui o foco recai sobre situações que seriam, "por definição", de uso individual, mas que acabam se transformando eventualmente em audiências coletivas. A situação escolhida para observação ocorre em espaços públicos onde a programação de TV pode ser acessada majoritariamente por telefones celulares do tipo "xing-ling"; dentro do escopo do artigo, a análise se deterá nos usos de celulares com TV em trens urbanos. 
Há uma certa dificuldade metodológica em se captar momentos de assistência televisiva menos óbvios, fora das rotinas domésticas, e que se multiplicam em inúmeras situações de audiência, como o dos passageiros que se sucedem em um táxi com TV. Na situação da audiência da TV no celular, em particular, o desafio da observação se intensifica pelo caráter errático de uma audiência que se encontra em trânsito e sem um momento predeterminado no qual se dará a vivência com o meio.

A cidade do Rio de Janeiro recebe um alto contingente de trabalhadores que moram em municípios vizinhos e que chegam a gastar cerca de quatro horas por dia no trajeto de ida e volta entre a casa e o local de trabalho. Parte dessas pessoas tem empregos de baixa qualificação profissional e utilizam como transporte urbano de massa os trens, ${ }^{2}$ o metrô e os ônibus.

Os trens da SuperVia que circulam na cidade são alvo de muitas críticas por parte da população - a má conservação dos vagões e os atrasos são reclamações constantes. Nas viagens, o ambiente é de alta sonoridade, especialmente pelos gritos dos muitos vendedores ambulantes que circulam pelos vagões oferecendo as mais diversas mercadorias. Os alimentos são os mais ofertados, mas outros produtos estão presentes, como DVDs, kits para pintar unhas e diversos artigos tecnológicos.

Pelo fato das viagens serem longas, um dos modos de passar o tempo é compartilhar com alguém algo que se esteja fazendo no celular. Em uma cena observada, uma mãe mostra o celular para a amiga com uma foto que vai ser postada no "Face (book)". Em outra situação, na qual três rapazes conversam, um deles pergunta ao colega se pode usar o seu próprio headphone no celular do outro, que está ouvindo uma rádio local no aparelho. A música toca alto o suficiente para que os que estão ao redor possam ouvir. Em várias outras cenas semelhantes, o celular serve a um propósito coletivo, ligado ao entretenimento e ao exercício de uma intensa sociabilidade entre os pares, não ficando restrito ao desfrute do dono do aparelho.

\footnotetext{
${ }^{2}$ O trabalho de campo se concentra até o momento no contexto da SuperVia, rede ferroviária que transporta passageiros dos municípios vizinhos à cidade do Rio de Janeiro.
} 
A novela Avenida Brasil - transmitida pela TV Globo no ano de 2012 e que teve altos índices de audiência aliados a uma maciça presença nas redes sociais - merece comentários mais detalhados em relação ao contexto de recepção abordado. Os que voltavam do trabalho mais tarde nos transportes coletivos ${ }^{3}$ assistiam à novela em seu aparelho celular, muitas vezes compartilhando com os que estavam ao redor o conteúdo transmitido, iniciando assim uma larga conversação sobre o programa. Destaco, nesse ponto, a recepção feita por empregadas domésticas. ${ }^{4}$

A trama da novela se desenvolveu a partir do mote da vingança da personagem Rita/Nina, maltratada na infância por Carminha, sua antiga madrasta. Para realizar seu plano, Rita se emprega como cozinheira na casa de Carminha e acaba tomando as dores das empregadas da casa, que eram constantemente humilhadas pela patroa.

Na volta para casa, no momento de assistir à novela no celular junto a outras empregadas, emergia um certo "sentimento de classe" na condenação desse grupo social ao autoritarismo e à arrogância da personagem Carminha. Era a hora de "falar mal" das patroas e de seus excessos de prepotência na relação com as empregadas, quando a conversa girava em torno de casos reais. As empregadas não participavam da intensa movimentação nas redes sociais provocada pela novela por não serem adeptas do Twitter, mas amplificavam a recepção do programa nas conversas diárias na ida e na volta do trabalho, tanto no momento em que assistiam no celular quanto naqueles em que apenas comentavam o capítulo do dia anterior. Eventualmente, essa conversa coletiva sobre a novela tinha continuidade na casa da patroa.

A conversa sobre programas de televisão pode se revelar um modo priviBlegiado de diálogo, troca de informações, julgamentos morais e conhecimento de novos estilos de vida entre os mundos das empregadas e de suas patroas (BARROS, 2007). Vale, nesse ponto, lembrar a ideia de "repertório compartilhado" conforme propõe Hamburger (1998), em

\footnotetext{
3 A novela iniciava pouco depois das nove horas da noite.

${ }^{4} \mathrm{O}$ material relativo à recepção da novela Avenida Brasil não foi coletado durante as viagens de trem, mas em conversas posteriores com empregadas domésticas.
} 
que o mais importante é o próprio sentimento de compartilhar em uma sociedade hierarquizada como a brasileira:

Enquanto a segregação social, econômica e cultural segmenta e divide a sociedade brasileira, a televisão acena a possibilidade de conexão, mesmo que virtual. Telespectadores de classes populares e dominantes compartilham a mesma fascinação com o que eles, em sintonia com o meio, denominam "modernidade" (HAMBURGER, 1998, p. 485).

A novela permitiu, ao longo dos anos, a consolidação de convenções formais de narrativa que são de amplo domínio do público. Diferentes interpretações são possíveis porque todos "sabem” ver novela (HAMBURGER, 1998, p. 483). A ideia de "repertório compartilhado", portanto, não implica em um consenso de sentido; ao contrário, chama atenção para o campo de negociações de significados que pode ser compreendido quando o foco de análise recai sobre a recepção.

Esse "repertório compartilhado", criado pelo fato da novela ser vista no país por todas as classes sociais, estrutura-se e se fortalece no dia a dia, nos momentos em que empregadas e patroas comentam e discutem o conteúdo de diversos programas e, em especial, das novelas.

Em relação à novela Avenida Brasil, o tema do relacionamento empregadas-patroas se tornou objeto de muitas conversas no ambiente de trabalho, onde, por um lado, a empregada não fazia a "catarse" em relação ao emprego doméstico que acontecia nos trens, mas aproveitava para comentar com sua patroa sobre os absurdos do comportamento autoritário e dos maus tratos impostos pela personagem Carminha às suas empregadas. Em um país com forte oralidade e intensa sociabilidade (DAMATTA, 1981) como o Brasil, tão importante quanto assistir à novela é poder falar sobre ela, especialmente quando o produto televisivo interessa a todas as classes sociais, como foi o caso de Avenida Brasil. O ato de assistir TV no celular leva para os espaços públicos a possibilidade de amplificar a conversa antes restrita às residências e ao ambiente de trabalho. Falar sobre o capítulo do dia anterior já era um hábito; poder assistir no celular no momento em que o programa era exibido 
aumentava o engajamento de todos que estavam no ambiente, criando, desse modo, uma grande conversa coletiva.

\section{Oralidade e usos coletivos em torno das mídias}

Podemos pensar, a partir desse ponto, a importância da oralidade na sociedade brasileira e como os fenômenos comunicacionais têm no país uma forte marca de sociabilidade e interação, antes mesmo do advento das novas mídias. Na verdade, estas acentuaram determinados aspectos culturais já existentes. O antropólogo Gilberto Freyre (1987), em seu clássico Casa Grande E Senzala, já enfatizava a forte oralidade da sociedade brasileira desde o período de colonização, expressa nas animadas conversas nas ruas e nas narrativas orais com as quais as escravas, grandes contadoras de histórias, divertiam os filhos dos senhores de engenho. Tratava-se de um contexto social mais afeito à conversa que à escrita, que sempre teve ares de excessiva formalidade ante a fala "mole" encontrada nas ruas, fruto das trocas culturais entre os grupos formadores do país - escravos, portugueses colonizadores e índios.

Lançando um olhar para momentos cotidianos da sociedade brasileira em que o consumo de mídia se dá de modo compartilhado, vale comentar uma cena típica na cidade do Rio de Janeiro, que é a leitura coletiva das notícias nos jornais expostos nas bancas. Os jornaleiros penduram os jornais diários no lado de fora das bancas pela manhã e as pessoas que passam se aglomeram em frente às manchetes, tecendo eventuais comentários sobre os diversos assuntos estampados nas primeiras páginas. Leem-se e comentam-se manchetes dos jornais diários sem que a compra seja necessariamente realizada.

Na pesquisa em andamento, comentada neste artigo, também foi possível observar uma variação dessa conversa coletiva em torno de uma mídia. Além do acompanhamento dos sujeitos em trens urbanos, a etnografia se estende a uma comunidade de baixa renda na cidade do Rio de Janeiro. No local estudado, um teleférico leva os moradores aos pontos mais altos da comunidade. A condutora do bondinho sempre deixava, dentro do transporte, um jornal popular que era lido e comentado por 
ela ou por algum outro passageiro, suscitando comentários de outras pessoas. Em uma cena observada no teleférico, a partir da leitura de seu próprio jornal, uma pessoa comentou de modo irônico e em voz alta sobre o comportamento de um polêmico jogador de futebol, ouvindo opiniões de apoio e reprovação de alguns passageiros. Nesse mesmo trajeto, outras pessoas liam uma manchete do jornal. O jornal não era lido de modo introspectivo; ao contrário, era comum a situação em que a pessoa lia o jornal e externalizava seu sentimento para os outros, esperando algum tipo de comentário. Assim, o jornal era lido em partes e comentado em grupo durante a curta viagem a caminho de casa.

Essa leitura "socializada" remete à contraposição feita por Chartier (1993) a respeito de possíveis modos de relação entre leitor e objeto lido. Para o autor, existe um tipo de leitura intensiva que marcou um período histórico em que a leitura era escassa e que se articula a várias práticas, como recitar o lido para outras pessoas. A ela se contrapõe a leitura extensiva, que teria se imposto a partir do século XVIII, na qual os textos passam a ser lidos individualmente, na intimidade e no silêncio. Chartier sugere que não teria havido propriamente a substituição da primeira modalidade pela segunda, mas que elas podem coexistir nas experiências com leitura em grupos sociais diferentes. Os relatos sobre a leitura socializada observada na experiência de campo poderiam, até certo ponto, serem associados a essa ideia de leitura extensiva, na qual o contexto coletivo é enfatizado através do compartilhamento do conteúdo lido dentro do grupo. No caso contemporâneo, o índice de leitura também é baixo no grupo social estudado - seja pela baixa escolaridade da população, seja por restrições econômicas que limitam a compra de jornais.

Alguns autores, em especial, preocuparam-se em enfatizar o ambiente sociocultural no qual as tecnologias de comunicação se inserem, convidando a um olhar mais aprofundado sobre as interações, redes e sociabilidades que preexistem às vivências com os meios e que se reconfiguram a partir daí. Miller e Horst (2006), em sua etnografia sobre celulares na Jamaica, mostraram como tais objetos são incorporados nas 
estratégias de fortalecimento de extensas redes de relacionamento já existentes antes da adoção de novas mídias. Winkin (1998), que também se insere nessa linha de estudos, pensa na "novidade" tecnológica dentro de quadros culturais específicos, enfocando interações mais amplas que revelam o aspecto propriamente coletivo das práticas estudadas, como seu estudo em escolas primárias e secundárias na Europa. Nesse trabalho, o autor acompanhou relações coletivas com o computador e não relações individuais "aluno-máquina", observando os comportamentos e as interações em torno do meio tecnológico. Analisando o ritual de troca de e-mails entre crianças de escolas localizadas na Inglaterra e na Itália, observou que o maior prazer dos alunos estava, de fato, no envio e na recepção das mensagens, sendo totalmente secundário o que estava sendo dito, por exemplo.

Em trabalho anterior a respeito de adeptos de games em lan houses populares no Rio de Janeiro (BARROS, 2009), foi possível observar um contexto de recepção em que a aprendizagem do jogo acontecia por intermédio de um forte compartilhamento coletivo. O grupo em questão era formado por jogadores do game World of Warcraft (WoW), classificado na categoria MMORPG (Massive Multiplayer Online Role-Playing Game - jogos on-line e em massa para múltiplos usuários). O uso dos computadores na lan chamava atenção por um aspecto específico - além dos usuários estarem conectados e interagirem com outros jogadores on-line, existia uma grande interação com as outras pessoas que estavam no ambiente físico da lan house. Os jovens, estivessem ou não diante do computador, comunicavam-se intensamente, trocando "dicas" sobre as melhores estratégias e ações a serem tomadas no decorrer do jogo. O "ensinamento" era passado por alguém que tivesse maior expertise no jogo, papel que era desempenhado alternadamente por múltiplos atores - os atendentes da lan e os jogadores mais experientes. Acontecia, em vários momentos, de a navegação ser realmente compartilhada, quando alguém tomava o mouse de quem estivesse diante do computador, jogando durante certo tempo para depois devolver o controle do jogo ao colega. O aprendizado girava em torno de dicas 
sobre a lógica geral do WoW, seu passo a passo, as melhores estratégias a serem adotadas, o significado de palavras e expressões em inglês e, ainda, a melhor forma de manusear o mouse e o teclado a fim de alcançar maior agilidade nos combates.

Podiam ser duas, três ou quatro pessoas ao redor de um mesmo computador, com uma "oficialmente" protagonizando a aventura, outra, de maior expertise, tomando o mouse em alguns momentos para avançar nas etapas, e terceiros fazendo comentários sobre o jogo ou simplesmente "zoando". De certo modo, existia ali um contraponto à ideia original de personal computer - no ambiente da lan house encontrei, até certo ponto, máquinas coletivas, funcionando de um modo colaborativo, como uma espécie de "computador pessoal compartilhado".

Nesse contexto de pesquisa, a plataforma de jogos on-line é apropriada de um modo coletivo no plano "físico", exacerbando o caráter já interativo do game. A interação e a aprendizagem coletiva do jogo que ocorre no espaço da lan house é resultado de uma audiência dinâmica, que flutua entre as máquinas, formando novos grupos no decorrer das horas. O jogador da lan house é, assim, afetado por uma larga sociabilidade que se estabelece ali, além da interação on-line proporcionada pelo jogo. Trata-se de um cenário onde a relação com o computador deve ser vista para além do plano individual - ou de uma estrita relação homem-máquina -, buscando o entendimento do fenômeno comunicacional sob uma ótica das interações, que mostram a importância da conversa e da sociabilidade na constituição da própria vivência com o meio.

\section{Dimensões comparativas entre Brasil e África do Sul}

É importante lembrar que a discussão sobre a ascensão econômica de segmentos da população - e de novos "mercados consumidores" - vai muito além do contexto brasileiro, sendo tema de amplo debate em diversos países em desenvolvimento, como a África do Sul e a Índia. Neste último país, por exemplo, o crescimento econômico de parte dos segmentos mais pobres da população tem entrado em choque com o antigo sistema de castas, que, embora abolido oficialmente da sociedade 
indiana em 1950, persiste como um forte elemento de hierarquização e inibição da mobilidade social.

Ao mesmo tempo que se procuram similaridades e distanciamentos entre os processos de mudanças socioeconômicas em curso, pode-se atentar para outros aspectos de cunho mais "tradicional" presentes em países do Atlântico Sul. Assim, deslocando a reflexão do Brasil para a África do Sul, alguns estudos apontam para a presença de práticas de consumo relacionadas à tecnologia que indicam pontos de contato com o contexto brasileiro estudado.

A pesquisa de Walton et al. (2012), por exemplo, investiga a sociabilidade entre jovens moradores de Khayelitsha, uma comunidade pobre localizada na periferia urbana da Cidade do Cabo, através de certos usos de celulares em um contexto no qual os aparelhos costumam ser compartilhados. Como mostram outros estudos junto a grupos de baixa renda (SMYTH et al., 2010; SILVA, 2010), o uso do bluetooth na comunidade aparece como um recurso importante ante os altos custos do acesso à internet. $\mathrm{O}$ estudo mostra de que forma o modo como a indústria pensa os usos dos objetos pode ficar muito distante das práticas sociais de alguns grupos. Assim, certos recursos dos aparelhos ligados a "proteção" e "privacidade" acabam por criar problemas em contextos como o sul-africano, em que a ênfase está no compartilhamento. Enquanto na esfera da produção do celular se pressupõe que a "privacidade pessoal" seja algo universalmente desejável, no cotidiano dos jovens pesquisados, o uso dos recursos de privacidade do aparelho pode gerar conflitos, seja por expressar um comportamento antissocial, ao dificultar o compartilhamento, seja por sugerir que a pessoa tenha "algo a esconder".

Um ponto importante a ser ressaltado é que o compartilhamento de celulares não deve ser visto, de modo determinista, como simples consequência da "escassez econômica", pois os usos coletivos podem ser observados mesmo em lugares pobres onde as pessoas têm seus celulares individuais. Tampouco essas práticas em conjunto devem ser vistas como inseridas em uma espécie de "cultura da comunhão", já que se pode observar a manutenção de mecanismos de distinção e de hierarquia, como 
no caso do estudo de Burrell (2010) realizado em Uganda, onde as mulheres são excluídas das práticas de compartilhamento de celulares.

Schoon (2013), por sua vez, realizou um estudo etnográfico junto a jovens de baixa renda na cidade de Grahamstown, na África do Sul, em um cenário econômico de alta taxa de desemprego. A autora mostra que os usos observados de celulares diferem em larga escala dos hábitos predominantes em países desenvolvidos, onde a posse dos aparelhos usualmente facilita a mobilidade, proporcionando o alargamento das barreiras geográficas e a libertação dos laços com a comunidade de origem. De modo diverso, no caso sul-africano estudado, não se vivencia a noção de "privacidade" encontrada nas classes médias, já que uma intensa vida social acontece no espaço da rua para observação de todos. Em Grahamstown, o uso dos celulares, com recursos amplamente utilizados, como os aplicativos de chat, acaba por intensificar as experiências locais, tornando os laços mais densos dentro da comunidade graças à incorporação da tecnologia em situações como os "rituais de fofoca e namoro". O resultado disso, segundo Schoon, é uma condição de "imobilidade", já que os jovens permanecem presos a fatos sociais definidos por raça, classe e gênero. Em estudo realizado em uma comunidade pobre na cidade do Rio de Janeiro (BARROS, 2009), encontramos resultados semelhantes aos de Schoon (2013) no que se refere a uma ênfase na sociabilidade local nos usos de redes sociais através de computadores. Nessa pesquisa, as postagens na rede social Orkut se referiam, primordialmente, a comentários e fotos sobre eventos ocorridos com amigos de escola ou da vizinhança, pessoas que se acabara de ver ou com as quais se acabara de falar, reforçando os vínculos já existentes. Chegava-se, inclusive, a negar a possibilidade de surgimento de uma "amizade verdadeira" no mundo virtual, como apareceu no discurso de um dos jovens informantes: "O amigo do dia a dia tá comigo, sabe o que eu faço, o que eu não faço, sabe o que eu gosto, sabe o que eu não gosto. Já amigo de internet não faz nem ideia do que eu gosto ou do que eu não gosto".

Assim, os estudos sul-africanos e brasileiros aqui comentados mostram, em seu conjunto, modos de apropriações tecnológicas que 
encontram na dimensão coletiva e compartilhada um palco privilegiado para as dinâmicas de sociabilidade local.

\section{Considerações finais}

O artigo procurou discutir certas práticas de consumo de tecnologia junto a grupos populares nas quais os usos coletivos aparecem como um aspecto central das dinâmicas culturais observadas.

Os usos abordados da mídia celular com TV ocorrem em um contexto cultural específico, marcado por forte oralidade e sociabilidade - o aparelho celular de uma pessoa fornece conteúdo de conversa e diversão para outros além do seu dono, estendendo o momento de recepção para um processo permanente de relações interpessoais. Como mostrou o exemplo das empregadas domésticas no caso da novela Avenida Brasil, assistir TV no celular durante as viagens de ida e volta do trabalho permite a amplificação da discussão das relações entre empregadas e patroas.

Após incorporar à investigação determinadas situações do contexto cultural sul-africano, sugere-se a necessidade de relativização do modo de consumo individual de bens comunicacionais na busca de uma maior compreensão dos usos coletivos relacionados a televisão, celulares e computadores. Trata-se de pensar em um modo mais amplo do que o da relação indivíduo-máquina, procurando enfatizar o jogo de interações que acontecem nessas práticas e nos sistemas culturais que servem de pano de fundo para as vivências em meios tecnológicos.

Nos estudos brasileiros e sul-africanos comentados, percebem-se usos de tecnologia que relativizam o modelo dominante em países desenvolvidos, onde os celulares são, usualmente, sinônimo de individualização e mobilidade geográfica e social. A descontinuidade entre as esferas da produção e do consumo acabam apontando para práticas de consumo de tecnologia orientadas a partir de uma lógica pública, coletiva e compartilhada. 


\section{Referências}

BARROS, C. Trocas, hierarquia e mediação: as dimensões culturais do consumo em um grupo de empregadas domésticas. 253 f. Tese (doutorado em Administração) - COPPEAD/Universidade Federal do Rio de Janeiro, Rio de Janeiro, 2007.

BARROS, C. Usos juvenis de computadores na lan da periferia: um estudo sobre cultura, sociabilidade e alteridade. In: $32^{\circ}$ CONGRESSO BRASILEIRO DE CIÊNCIAS DA COMUNICAÇÃO. Anais... Curitiba: Intercom, 2009. Disponível em: http://www. intercom.org.br/papers/nacionais/2009/lista_area_DT6-CU.htm.

BURRELL, J. Evaluating Shared Access: social equality and the circulation of mobile phones in rural Uganda. Journal of Computer-Mediated Communication, v. 15, n. 2, p. 230-250, 2010.

CHARTIER, R. Du livre au lire. In: CHARTIER, R. (Org.). Pratiques de la lecture. Paris: Editions Payot \& Rivages, 1993.

DAMATTA, R. Carnavais, malandros e heróis: por uma sociologia do dilema brasileiro. 3. ed. Rio de Janeiro: Zahar, 1981.

FREYRE, G. Casa Grande ๒ Senzala. 25. ed. Rio de Janeiro: José Olympio, 1987.

GASTALDO, E. 'O complô da torcida': futebol e performance masculina em bares. Horizontes Antropológicos, v. 11, n. 24, p. 107-123, 2005.

GOFFMAN, E. Behavior in public places. Nova York: The Free Press, 1963.

HAMBURGER, E. Diluindo fronteiras: a televisão e as novelas no cotidiano. In: SCHWARCZ, L. (Org.). História da vida privada no Brasil: contrastes da intimidade contemporânea. v. 4. São Paulo: Companhia das Letras, 1998.

MILLER, D. Material culture and mass consumption. Oxford: Blackwell, 1987.

MILLER, D.; HORST, H. The Cell Phone: An Anthropology of Communication. Oxford: Berg, 2006.

ROCHA, E. Magia e capitalismo. São Paulo: Brasiliense, 1985.

SAHLINS, M. Cultura e Razão Prática. Rio de Janeiro: Zahar, 1979.

SCHOON, A. (Im)mobile phones: "Stuckness" and mobile phones in a neighbourhood in the global south. In: ICA MOBILE PRE-CONFERENCE. Anais... Londres: London School of Economics, jun. 2013. p. 1-13.

SILVA, S. R. Estar no tempo, estar no mundo: a vida social dos telefones celulares em um grupo popular. 435 f. Tese (doutorado em Antropologia) - Universidade Federal de Santa Catarina, Florianópolis, 2010.

SILVEIRA, F. Sobre a 'naturalização' da domesticidade televisiva: uma problematização e um protocolo para a observação empírica. Alceu, v. 4, n. 8, p. 65-77, 2004.

SILVERSTONE, R. Televisión y vida cotidiana. Buenos Aires: Amorrortu, 1996.

SIMMEL, G. Fashion. The American Journal of Sociology, v. 62, n. 6, p. 541-558, 1957.

SMYTH, T. N.; KUMAR, S.; MEDHI, I.; TOYAMA, K. Where there's a will there's a way: mobile media sharing in urban India. In: $28^{\mathrm{TH}}$ INTERNATIONAL CONFERENCE ON HUMAN FACTORS IN COMPUTING SYSTEMS. Anais... Atlanta, Geórgia, abr. 2010. p. 753-762. 
148 DA PRODUÇÃO AO CONSUMO

TUFTE, T. Questões a serem estudadas em estudos etnográficos de mídia: mediações e hibridização cultural na vida cotidiana. In: LOPES, M. I. V. (Org.). Temas contemporâneos em comunicação. São Paulo: Edicon: Intercom, 1997.

WALTON, M.; HAßREITER, S.; MARSDEN, G.; ALLEN, S. Degrees of Sharing: Proximate Media Sharing and Messaging by Young People in Khayelitsha. In: MOBILEHCI'12. Anais... São Francisco, Califórnia, set. 2012. p. 403-412.

WINKIN, Y. A nova comunicação: da teoria ao trabalho de campo. Campinas, SP: Papirus, 1998.

Data de submissão: 01/07/2015

Data de aceite: 22/10/2015 